\title{
Seasonal variation in circulating testosterone and oestrogens of wild-caught California ground squirrels (Spermophilus beecheyi)
}

\author{
K. E. Holekamp* and F. Talamantes† \\ Department of Biology, Sinsheimer Laboratories, University of California, Santa Cruz, CA 95064, \\ $U S A$
}

\begin{abstract}
Summary. Blood samples were obtained each month for 18 months in 1984-85 from wild-caught California ground squirrels. Circulating testosterone and total oestrogens were extracted from the plasma, measured by radioimmunoassay and compared with concurrent changes in plasma progesterone and prolactin in the same individuals. Male plasma testosterone concentrations peaked in January, shortly before mating, whereas female testosterone concentrations were low throughout the year. Female plasma oestrogen concentrations peaked in February, during the mating period. Juvenile males exhibited a transient increase in circulating testosterone in September, followed by testis growth, preputial separation, and the appearance of epididymal spermatozoa. Juvenile females exhibited a transient increase in circulating oestrogens in November. By the start of the first mating season after their births, neither juvenile males nor females differed significantly from same-sex adults with respect to plasma concentrations of oestrogen or testosterone. Plasma concentrations of progesterone and prolactin in killed individuals were similar to those obtained in previous studies of free-living $S$. beecheyi. Mean plasma concentrations of all measured hormones varied significantly with reproductive condition in adults of both sexes.
\end{abstract}

Keywords: oestrogens; seasonality; Spermophilus beecheyi; testosterone; ground squirrel

\section{Introduction}

Seasonal fluctuations in circulating concentrations of reproductive hormones have been described for various mammals (e.g. see Lincoln, 1981). In the present study, changing concentrations of gonadal steroids in plasma from male and female California ground squirrels (Spermophilus beecheyi) were measured throughout their annual cycle by radioimmunoassay (RIA) using killed, wild-caught individuals. Monthly mean values of circulating testosterone and total oestrogens grouped by age and sex of $S$. beecheyi are presented. Seasonal changes in plasma concentrations of these hormones are related to concurrent plasma concentrations of prolactin and progesterone in the same individuals.

\section{Materials and Methods}

\section{Animals}

The study was conducted on the lower campus of the University of California at Santa Cruz (UCSC) ( $37^{\circ} \mathrm{N}$, $122^{\circ} \mathrm{W}$; Santa Cruz County, California; mean elevation $120 \mathrm{~m}$ ). This is an area of open, rolling grassland, grazed for 4-8 weeks each year by domestic cattle. For a detailed description of the study area, see Holekamp \& Nunes (1989).

*Dept of Ornithology \& Mammalogy, California Academy of Sciences, San Francisco, CA 94118, USA.

†Reprint requests. 
Descriptions of the annual cycles of reproduction and dormancy in the $S$. beecheyi population at UCSC are given in Holekamp et al. (1988a) and Holekamp \& Nunes (1989). Mating occurs in February and early March, followed by a 25-30-day gestation period (Grinnel \& Dixon, 1918; Edge, 1931) and a 5-6-week lactation interval. Adults of both sexes aestivate each year from summer to autumn, but juveniles remain surface-active from weaning to the end of their first breeding season.

The animals used in this study were collected from colonies peripheral to those in our primary UCSC study area where free-living individuals of $S$. beecheyi have been intensively observed and their blood sampled regularly via femoral venepuncture (Holekamp et al., 1988a, b; Holekamp \& Nunes, 1989). Colonies are defined as groups of individuals living in close association at aggregations of burrow entrances. Each aggregation of animals and burrows at UCSC was separated from others by $100-250 \mathrm{~m}$ of grassland uninhabited by ground squirrels.

\section{Trapping and handling techniques}

From January 1984 to June 1985, ground squirrels at UCSC were captured each month in Tomahawk live-traps baited with grain. Two-hundred and sixteen males and 256 females were collected during the 18 month study period and all were sampled for plasma hormone content. Traps were set at $08: 00 \mathrm{~h}$ and all animals were collected from traps by 11:00 h and removed to our UCSC laboratory. They were then anaesthetized by Ketamine injection, weighed $( \pm 2 \mathrm{~g})$ with a Pesola spring balance and examined for wounds, and their reproductive condition was recorded. Monitored indices of female reproductive condition at each capture included nipple size, shape, colour and exposure, and vulval condition. Monitored indices of male reproductive condition included testis length $( \pm 1 \mathrm{~mm})$ and descent, degree of preputial separation (Korenbrot et al., 1977) and scrotal sac pigmentation. Immediately after being weighed and examined, all animals were killed by decapitation and their trunk blood was collected for hormone assays. The mean time between capture and death was $1.6( \pm 0 \cdot 4) \mathrm{h}$.

In males, the right testis and epididymis were dissected out and the testis length was measured with calipers. Epididymal contents were examined under a light microscope and the presence of mature spermatozoa was recorded. In females, the entire reproductive tract was dissected out and opened for counting placental scars and/or embryos, as described by Tomich (1962). Females whose uterine horns exhibited only one set of placental scars were considered primiparous, whereas those whose uteri exhibited $>1$ set of scars were considered multiparous (Tomich, 1962)

\section{Reproductive status}

The trapped animals were assigned a reproductive status according to the following criteria.

(1) Mating females $(n=7)$ had copulatory 'plugs' in their vaginae and/or their vulvae were swollen, perforate, moist and turgid, as described by Fitch (1948) and Tomich (1962). Data from mating females were obtained in late February and early March.

(2) Pregnant females $(n=12)$ had visible fetuses in their uteri. During pregnancy, the swelling of the external genitalia subsided, but late in the gestation interval the nipples started to enlarge. Data from pregnant females were obtained in late March and early April.

(3) Lactating females $(n=14)$ were those in which milk could be expressed from one or more teats during handling. During lactation the nipples became enlarged, bare, dark, and roughened. Data from lactating females were obtained in April.

(4) Non-reproductive females $(n=30)$ were adults in which the vaginae were imperforate, and the nipples were either minute, light-coloured, and completely fur-covered or shrivelled, dark, horny knobs (Fitch, 1948). Data from nonreproductive females were obtained in January.

(5) Non-reproductive males $(n=11)$ were adults (as indicated by complete separation of the penis from its preputial sheath; Korenbrot et al., 1977) with non-scrotal testes $<20 \mathrm{~mm}$ long. The scrotal sacs of these males were heavily fur-covered, and lightly pigmented. Data from these animals were obtained in April and May.

(6) Reproductively active males $(n=77)$ were adults with scrotal testes $>20 \mathrm{~mm}$ long. Scrotal sacs of these males were sparsely fur-covered and darkly pigmented. Data from these animals were obtained between 1 January and 30 March.

\section{Age determination}

Animals were assigned to age classes based on body mass (Holekamp \& Nunes, 1989), prior live-trapping records and/or appearance of the reproductive tract, according to Tomich (1962). 'Juveniles' were individuals that appeared to have been born within the previous 12 months, 'adults' were older animals. Only animals that could be assigned positively to one of these 2 age classes were used in analyses involving age groups. In total, 110 males and 122 females were identified as yearlings, and 97 males and 116 females were identified as adults based on the above criteria.

\section{Radioimmunoassays}

Whole blood was centrifuged for $8 \mathrm{~min}$ at $7000 \mathrm{~g}$. Plasma samples were then collected and stored frozen until assayed in duplicate for hormone content. Radioimmunoassays (RIA) were used to measure plasma concentrations of 
testosterone and oestrogens. Both assays used steroid assay buffer, ${ }^{125} \mathrm{I}$-labelled tracers, and primary antibodies from Radioassay Systems Laboratories (RSL) of Carson, CA. Assay buffer was $0.005 \%$ rabbit gamma globulins in $0 \cdot 1 \mathrm{M}$ phosphosaline-gelatin buffer, $\mathrm{pH} 7 \cdot 0$. Serial dilutions of pooled S. beecheyi plasma displaced ${ }^{125}$ I-labelled steroids in a parallel manner with standards provided by RSL in both assays, as did standards made from stripped, spiked plasma. Intra-assay coefficients of variation were estimated from replicate determinations of 2 quality control plasmas in each assay. Sensitivity of each assay was estimated as the lowest standard hormone concentration differing from replicate determinations of zero by 2 standard deviations.

Testosterone assay. Testosterone was extracted from $100 \mu$ l plasma samples in 15 volumes of hexane:benzene (2:1). Aqueous phase separation was accomplished by freezing and decanting each sample. Extraction efficiency was evaluated using stripped plasma samples spiked with $1 \mathrm{ng}$ and $5 \mathrm{ng}$ testosterone $/ \mathrm{ml}$ prior to each extraction. Mean extraction efficiency was $95.2 \%$ for $5 \mathrm{ng} / \mathrm{ml}$ samples and $96.5 \%$ for $1 \mathrm{ng} / \mathrm{ml} \mathrm{samples}(n=12)$. Standard curves were constructed from RSL standards of $0 \cdot 1,0 \cdot 25,0 \cdot 5,1 \cdot 0,2 \cdot 5,5$, and $10 \mathrm{ng}$ testosterone/ml. Quality control tubes containing extracted samples of 5 and $1 \mathrm{ng}$ testosterone/ml were run with each assay. Tracer was ${ }^{125} \mathrm{I}$-labelled testosterone, diluted with assay buffer to yield 10000 c.p.m. in $200 \mu$ l.

Fifty $\mu \mathrm{l}$ of standards, unknowns, or controls were added to $50 \mu \mathrm{l}$ buffer, $200 \mu \mathrm{l}$ tracer, $500 \mu \mathrm{l}$ primary antibody (diluted 1:4000000), and $100 \mu \mathrm{l}$ sex-binding globulin inhibitor (RSL). These reagents were vortexed, and incubated together for $2 \mathrm{~h}$ at $37^{\circ} \mathrm{C}$. Then $100 \mu \mathrm{l}$ of goat anti-rabbit gamma globulin (GAR) diluted (1:7) in assay buffer was added to each tube and vortexed. After a second incubation for $1 \mathrm{~h}$ at $37^{\circ} \mathrm{C}$, all assay tubes were centrifuged at $1000 \mathrm{~g}$ for $15 \mathrm{~min}$, supernatants aspirated and radioactivity in precipitants measured in an Iso-Data 20/20 series gamma counter.

Mean nonspecific binding in 12 assays was $8 \%$. The intra-assay coefficient of variation in this assay was $\mathbf{4 \cdot 2} \%$. The interassay coefficient of variation was $6.8 \%$ for $1 \mathrm{ng}$ testosterone $/ \mathrm{ml}$, and $7.0 \%$ for $5 \mathrm{ng}$ testosterone $/ \mathrm{ml}$. Assay sensitivity was $0.25 \mathrm{ng} / \mathrm{ml}$.

Total oestrogens. Oestrogens were extracted from $0.6 \mathrm{ml}$ plasma in $6 \mathrm{ml}$ ethyl acetate:hexane (3:2). After vigorous shaking for $2 \mathrm{~h}, 500 \mu \mathrm{l}$ samples were drawn from each tube, lyophylized and reconstituted with $1 \mathrm{ml}$ assay buffer. Duplicate $0.5 \mathrm{ml}$ aliquots were used for assay samples. Mean extraction efficiencies, estimated from stripped plasma aliquots spiked with 10 and $50 \mathrm{pg}$ oestradiol $-17 \beta / \mathrm{ml}$ were $80 \cdot 1$ and $87.9 \%$, respectively.

Standard curves were constructed from standards of $3 \cdot 9,7 \cdot 8,15 \cdot 6,31 \cdot 3,62 \cdot 5,125,250,500$, and $1000 \mathrm{pg}$ oestradiol- $17 \beta / \mathrm{ml}$. Quality control tubes containing extracted samples of 20 and $100 \mathrm{pg}$ oestradiol $-17 \beta / \mathrm{ml}$ were run with each assay. Tracer was ${ }^{125} \mathrm{I}$-labelled oestradiol-17及, diluted with buffer to yield 10000 c.p.m. in $100 \mu 1$. Five hundred $\mathrm{ml}$ of standards, unknowns, or controls was added to $100 \mu \mathrm{l}$ primary antibody, vortexed, and incubated for $24 \mathrm{~h}$. One hundred $\mathrm{ml}$ tracer was then added, and the tubes were vortexed and incubated for a further $2 \mathrm{~h}$. One hundred $\mu \mathrm{l} \mathrm{GAR}$ (diluted 1:7) were added, tubes vortexed, and incubated for $1 \mathrm{~h}$. All incubations in this assay were performed at room temperature $\left(22-25^{\circ} \mathrm{C}\right)$. Tubes were then centrifuged, supernatants aspirated and pellets counted.

Mean nonspecific binding in 7 assays was $7.7 \%$. The intra-assay coefficient of variation was $6.9 \%$. The interassay coefficient of variation was $12.6 \%$ for $20 \mathrm{pg} / \mathrm{ml}$, and $10.8 \%$ for $100 \mathrm{pg} / \mathrm{ml}$. Assay sensitivity was $7.8 \mathrm{pg} / \mathrm{ml}$.

Progesterone and prolactin. Methods for the progesterone RIA were as described by Holekamp et al. (1988b), those for the prolactin assay as described by Thordarson et al. (1987). Mean sensitivity of the progesterone assay was $0 \cdot 10 \mathrm{ng} / \mathrm{ml}$. Coefficients of variation between assays for 4 sets of control tubes ranged from 10 to $12.5 \%$. Coefficients of variation within progesterone assays were $3-7 \%$. Mean sensitivity of the prolactin assay was $0.21 \mathrm{ng} / \mathrm{ml}$. The intraassay coefficient of variation ranged from $2 \cdot 3$ to $5 \cdot 9 \%$. Coefficients of variation between prolactin assays ranged from 13.6 to $14.9 \%$.

\section{Statistical analysis}

Data were expressed as means \pm standard errors (s.e.m.), and comparisons of data grouped by age class or reproductive status were evaluated using analysis of variance (ANOVA; Keppel, 1973). Mean differences between the 2 male reproductive status groups were evaluated with 2-tailed Student's $t$ tests. Mean differences between the 4 female groups were evaluated with Tukey's Critical Range (TCR) tests, as were differences between months for each age-sex group comparison for which omnibus $\mathbf{F}$ values were significant. Mean differences were considered significant when $P<0.05$.

\section{Results}

Concentrations of testosterone in plasma of males peaked in January and were already declining when mating occurred in February and early March (Fig. 1a). Although mean testosterone concentrations in adult males tended to be higher than those of juvenile males during the latter group's first breeding season, no significant differences occurred between male age groups during the months in which both groups were concurrently surface-active (Fig. 1a: $F=2 \cdot 349 ; 9=$ d.f.; 
$P>0.05)$. In females, testosterone concentrations were low throughout the year and no significant differences were found between months, or between adult and juvenile females (Fig. $1 \mathrm{~b}: \mathrm{F}=1 \cdot 288$; $7=$ d.f.; $P>0.05$ ).
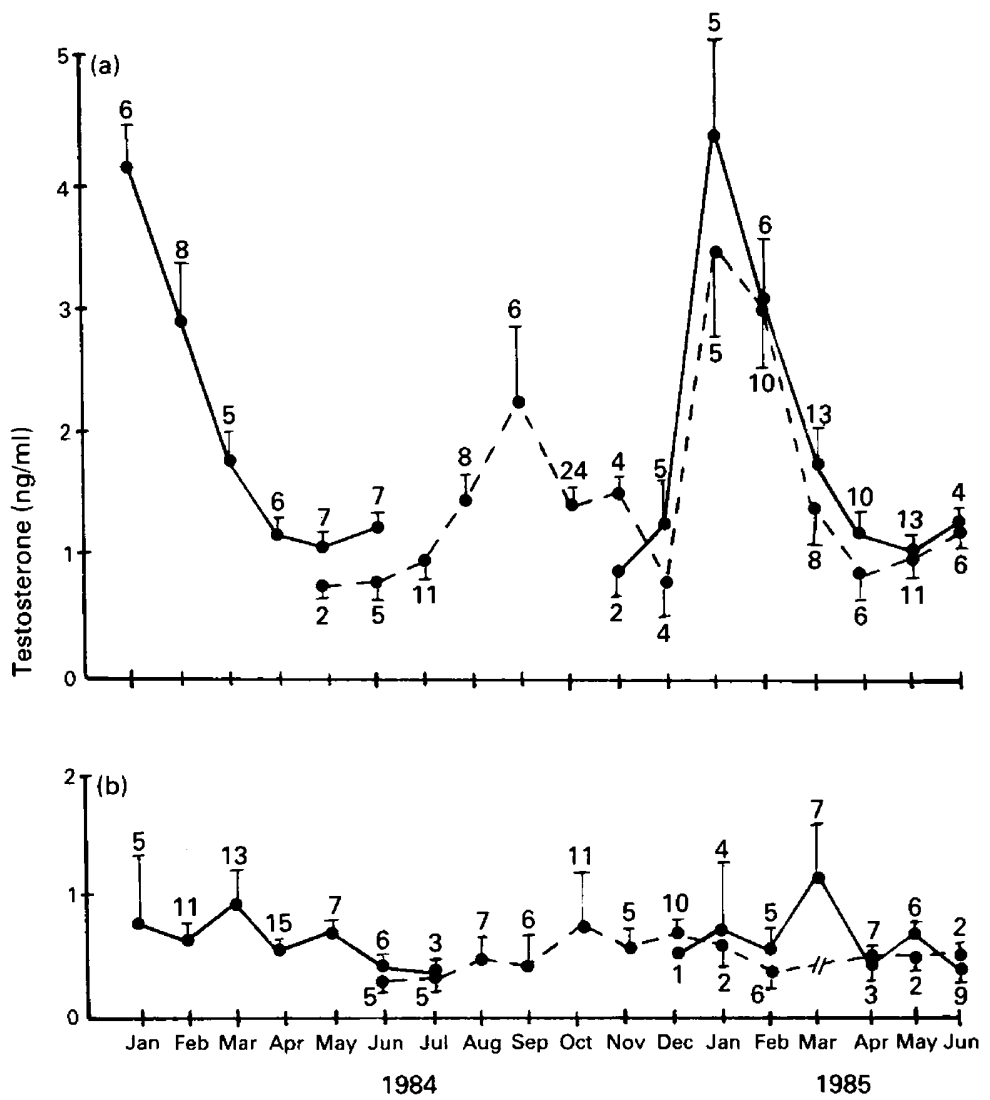

Fig. 1. Mean plasma testosterone (T) values obtained between January 1984 and June 1985, in adult (-) and juvenile (-- ) (a) male and (b) female Spermophilus beecheyi. Numbers indicate sample sizes. Data points and error bars represent means \pm s.e.m. Missing data points for adults indicate aestivation.

Testis length, sperm production, and plasma concentrations of testosterone and prolactin showed clear fluctuations in the adult males during their 8-month period of surface activity (Fig. 2). Plasma testosterone concentrations were low and the testes were small when adults emerged from aestivation in November and December. These measurements were similarly low when males reentered aestivation the following June. Although none of the adult males examined late in the active season had mature epididymal spermatozoa, epididymes from $\sim 50 \%$ of the males examined on emerging from aestivation contained mature spermatozoa. This suggests that spermatogenesis begins before males emerge from aestivation in $S$. beecheyi, as in S. lateralis (Barnes et al., 1986). All adult males examined in January, when plasma testosterone concentrations were highest, had mature epididymal spermatozoa, as did all males examined during the February-March mating period, when testosterone concentrations were declining (Fig. 2a). Testis length peaked in February. Prolactin concentrations in plasma of males differed significantly between months, increasing sharply in February and March, when testosterone concentrations were declining (F $=10.43 ; 7=$ d.f.; $P<0.001$ ). 

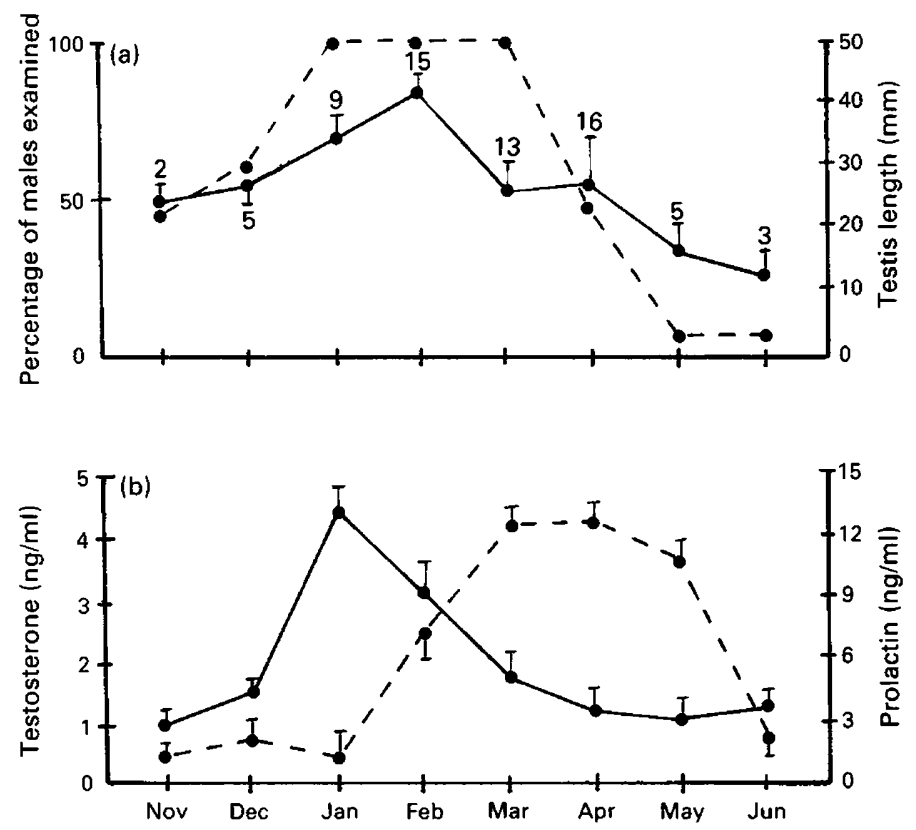

Fig. 2. (a) Mean monthly values for testis length in killed Spermophilus beecheyi ( $\longrightarrow$ ) and percentage of adult males examined each month found with mature epididymal spermatozoa $(--)$ and (b) mean plasma testosterone (-) and prolactin $(---)$ values in killed adult males of Spermophilus beecheyi. Sample sizes (numbers) are the same in (a) and (b). Adult males emerged from summer aestivation in late October or November and re-entered aestivation in June or July.

Males born in March or April first appeared above ground in May or June with tiny testes and low plasma testosterone concentrations (Fig. 3). None of the juvenile males examined exhibited either preputial separation (Korenbrot et al., 1977) or mature epididymal spermatozoa until they had been surface-active for at least 6 months (Fig. 3a). However, in September, juveniles had testosterone concentrations significantly higher than those trapped in July or October (Fig. 3b: $\mathrm{F}=7.349 ; 8=$ d.f.; $P<0.05 ; \mathrm{TCR}=0.69$ ). Thus juvenile males exhibited a transient rise in testosterone concentrations in August and September, followed shortly by increases in testis length, preputial separation and occurrence of mature epididymal spermatozoa (Fig. 3a, b). Mean plasma testosterone measured in juvenile males trapped in January was also significantly higher than in December. By January, males born the preceding spring were indistinguishable from older males by any of the measurements presented in Fig. 3.

Plasma oestrogen concentrations differed significantly between months in females (Fig. 4: $\mathrm{F}=7.049 ; 17=$ d.f.; $P<0.001 ;$ TCR $=187$ ), peak concentrations occurring in February. Oestrogen concentrations were lowest in newly emerged juvenile females (2-3 months old). Significant differences between concurrently active adult and juvenile females were observed only in June and December 1984 (Student's $t$ test; $P<0.05$ ). After December, the 2 female age groups could not be distinguished by this measure. Among juvenile females, a transient increase in plasma oestrogen concentrations was found in November compared with October or December. After November, circulating oestrogen concentrations declined again in juvenile females until the onset of their first mating period in February (Fig. 4). Mean size of the current or most recent litter in killed females, as indicated by embryo or placental scar counts, was $6 \cdot 7( \pm 0 \cdot 3 ; n=26)$ for primiparous animals and $7.9( \pm 0.3 ; n=47)$ for multiparous females $(\mathrm{F}=2.31 ; 71=$ d.f.; $P=0.082)$.

In wild-caught adult females, circulating concentrations of oestrogen, progesterone and prolactin were low when adults first emerged from aestivation in December (Fig. 5), increased during 

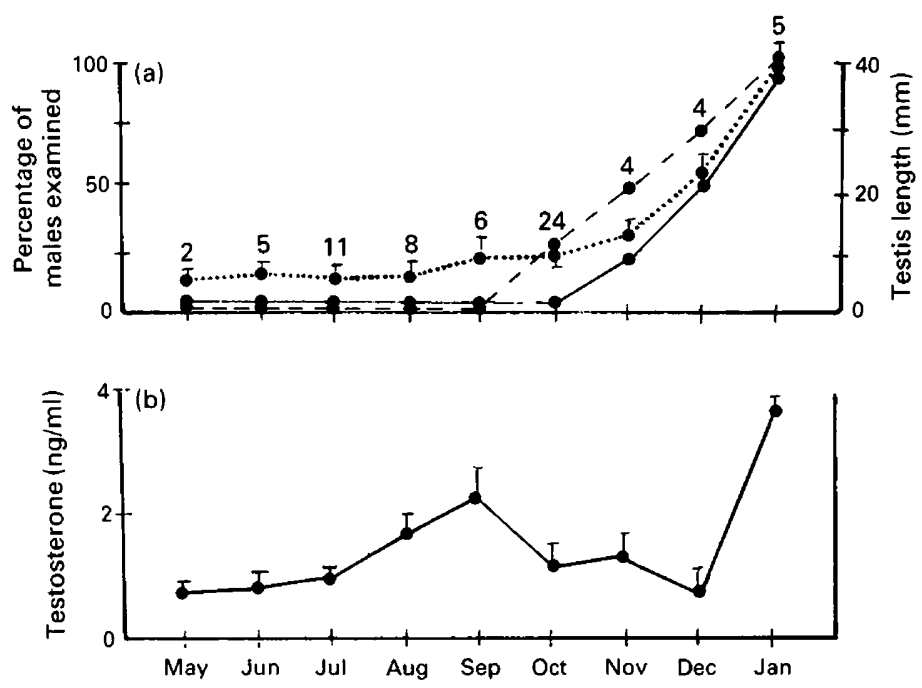

Fig. 3. (a) Monthly mean values for testis length ( $\cdots$ ); percentage of juvenile males examined each month found with mature epididymal spermatozoa $(-)$ and percentage of juvenile males examined each month found with complete preputial separation (---); and (b) mean plasma testosterone values in killed juvenile male Spermophilus beecheyi. Young were born each year in late March or early April and first emerged above ground in May or June. Sample sizes (numbers) are the same for all measurements.

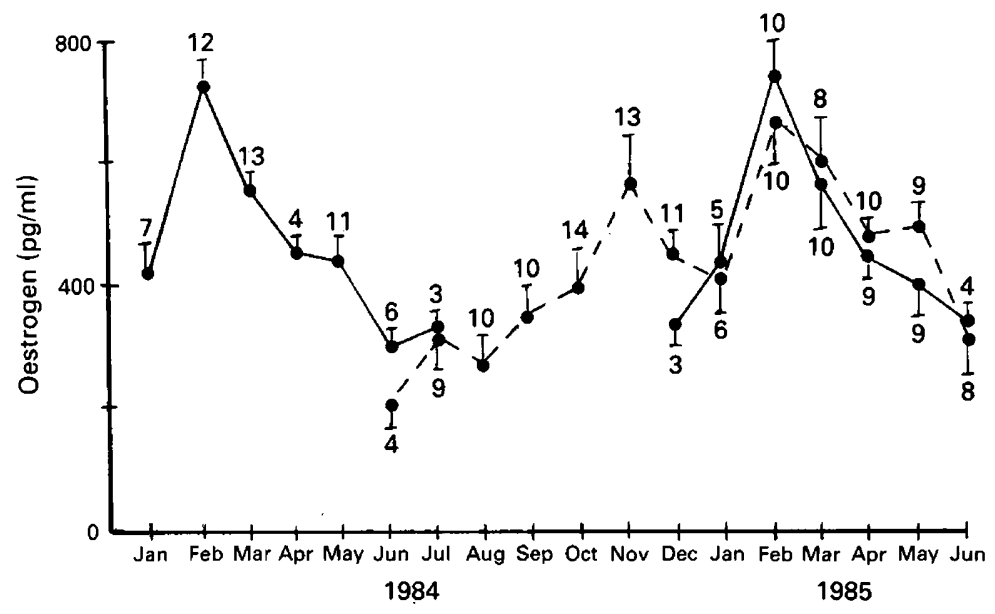

Fig. 4. Mean plasma values obtained between January 1984 and June 1985 for total oestrogens in adult (-) and juvenile (-- ) female Spermophilus beecheyi. Missing data points for adults indicate aestivation. Numbers indicate sample sizes.

the breeding season, then declined again prior to the females' return to aestivation in July. Oestrogen concentrations peaked first, during the mating period, and returned to its annual nadir by June (F $=7.049 ; 7=$ d.f.; $P<0.001 ;$ TCR $=206$ ). Plasma prolactin and progesterone concentrations increased during March, as oestrogen concentrations were declining. Progesterone concentrations increased significantly after mating, declined around the time of parturition (April), and then rose again during the lactation period $(\mathrm{F}=8.46 ; 7=$ d.f.; $P<0.001$; TCR $=3.74)$. Prolactin concentrations increased during pregnancy, peaked during lactation (April-May) and then declined 


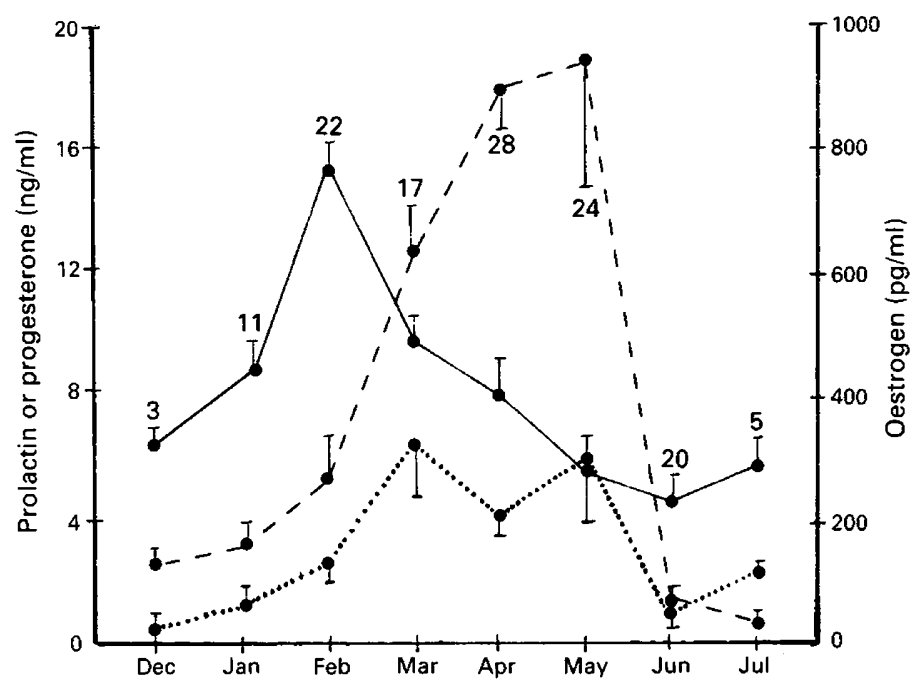

Fig. 5. Plasma profiles in killed adult female Spermophilus beecheyi of circulating prolactin $(--)$, progesterone $(\cdots)$, and oestrogen (-). Sample sizes (numbers) are the same for all hormones. Adult females emerged from aestivation in late November or December and re-entered aestivation in July.

rapidly in June when the annual female reproductive cycle ended $(\mathrm{F}=9.563 ; 7=$ d.f.; $P<0.001$; TCR $=8 \cdot 66$ ).

Mean plasma concentrations of the 4 hormones monitored in adult females varied significantly with reproductive condition (omnibus $F$ values for female hormone comparisons were significant, $P<0.05 ; 3=$ d.f.; ANOVA. Tukey's Critical Ranges were 166 for total oestrogens, 3.47 for progesterone, 8.06 for prolactin and 0.40 for testosterone: Fig. 6a,d). Progesterone and prolactin concentrations were higher in mating females than in nonreproductive females. Both were highest during pregnancy and lactation. By contrast, oestrogen concentrations peaked during mating. Plasma testosterone concentrations were significantly higher in pregnant females than in those in other reproductive conditions. Mean adult male plasma values for testosterone and prolactin were significantly higher $(P<0.05,2$-tailed Student's $t$ test $)$ in reproductively active than in other individuals (Fig. 6e, f).

\section{Discussion}

The data demonstrate seasonal changes in circulating gonadal steroids in $S$. beecheyi, as well as relative hormone concentrations in animals of different age classes and reproductive conditions. Data collected by others (e.g. Wesson et al., 1979) indicate that circulating steroid concentrations in some mammals may be increased by the stress of capture and handling. The effects of capture or handling on plasma hormone concentrations were not directly examined in our study. These effects might have been considerable because the mean time between capture and death was $1.6 \mathrm{~h}$, so the absolute plasma hormone values presented here must be viewed with some caution. However, the annual peaks and troughs in circulating hormone concentrations apparent in our data, and their temporal relationships to such known reproductive events as mating, pregnancy, and lactation, suggest that effects on measured hormone concentrations of reproductive condition and time of year were substantially greater than stress effects induced by capture and handling.

Seasonal changes in plasma testosterone concentrations have been reported for captive populations of Spermophilus lateralis (Licht et al., 1982; Barnes, 1986), S. beldingi (Bushberg \& Holmes, 

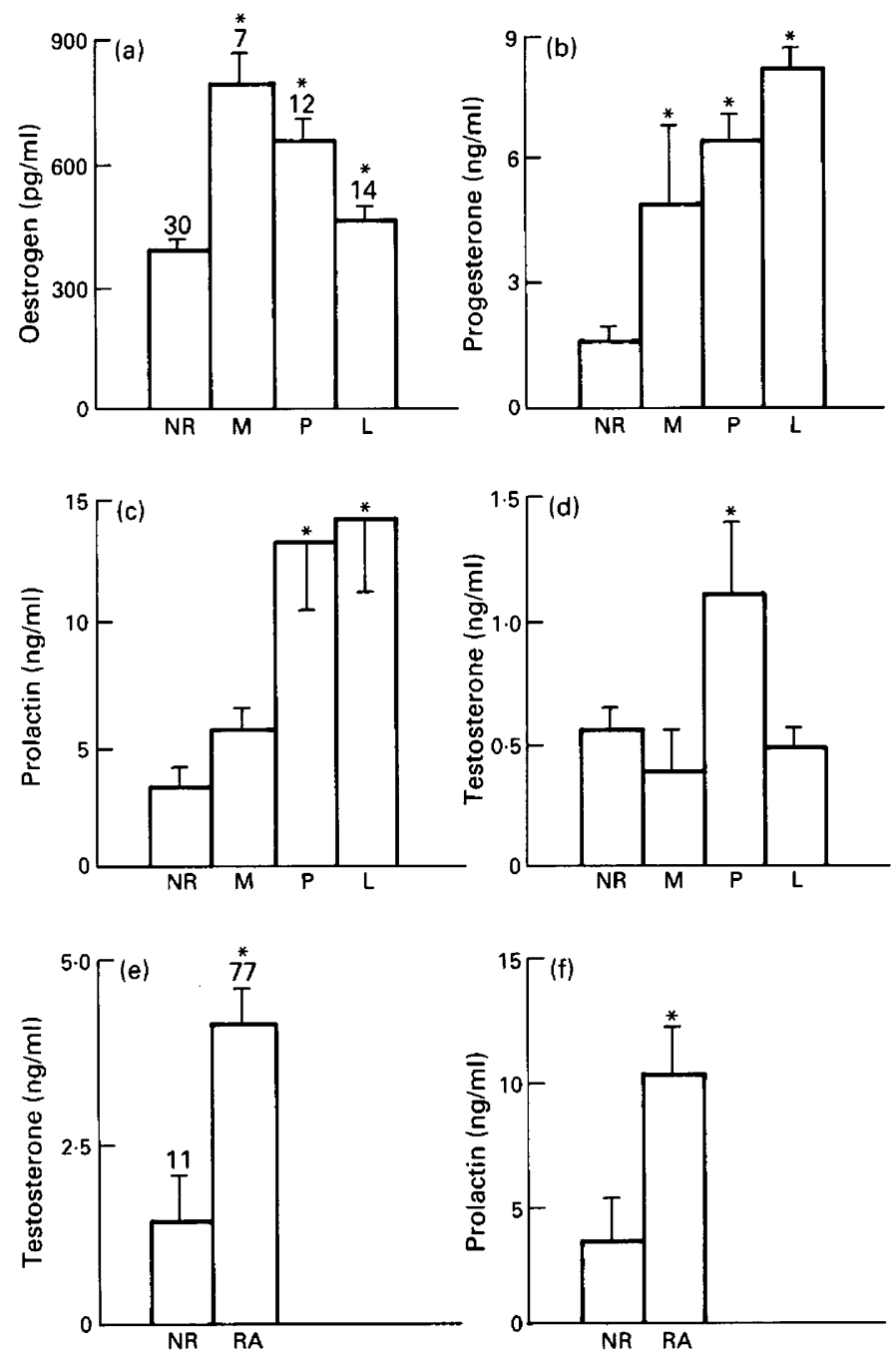

Fig. 6. Mean values of circulating oestrogens, progesterone, testosterone and prolactin in female (a-d) and male (e-f) Spermophilus beecheyi assigned to different reproductive status groups. RA, reproductively active, NR, nonreproductive, $M$, mating, $\mathrm{P}$, pregnant and $\mathrm{L}$, lactating. Data represent means \pm s.e.m. Sample sizes for each sex were identical for all hormones measured. *Significantly different from the mean value for nonreproductive animals for that hormone.

1985), and Sciurus carolinensis (Siwela \& Tam, 1981). In those species, male testosterone profiles are similar to those described here for $S$. beecheyi in that testosterone concentrations peak shortly before or during the mating period.

Prolactin concentrations in free-living adult and juvenile $S$. beecheyi during the breeding season have been published previously (Holekamp et al., 1988a), as have those for plasma progesterone in females (Holekamp et al., 1988b). Earlier, data showed that peak prolactin concentrations in freeliving male $S$. beecheyi occurred in March, immediately after mating activity ceased (Holekamp et al., 1988a). Peak plasma prolactin concentrations in males did not differ significantly from peak (lactational) prolactin concentrations in female free-living animals. We suggested previously (Holekamp et al., 1988a) that high circulating prolactin concentrations in males might suppress 
copulatory behaviour and inhibit testis function, as they appear to do in rams (e.g. Almeida \& Lincoln, 1984). Our present data on testosterone concentrations, testis length and sperm production support this hypothesis.

Plasma testosterone concentrations in male $S$. beecheyi exhibited a well-defined cycle of change, peaking in January. The pattern of changing testis length we observed in $S$. beecheyi has been described previously for this species (Tomich, 1962) and for other ground squirrels (Spermophilus tridecemlineatus; Wells, 1935; Morton \& Gallup, 1975; S. beldingi, Bushberg \& Holmes, 1985; S. lateralis, McKeever, 1964; Kenagy, 1980). The period of greatest testis length in $S$. beecheyi was similar to that reported for other ground-dwelling sciurids (e.g. Kenagy, 1980). Testicular recrudescence is initiated before emergence from hibernation in other ground squirrels (Davis, 1976; Kenagy, 1980; Bushberg \& Holmes, 1985; Barnes, 1986; Barnes et al., 1986), and this may occur in $S$. beecheyi. However, many UCSC males still had small testes when they emerged from aestivation in the autumn and recrudescence continued from November to February. This interspecific difference might be related to the fact that male $S$. beecheyi can be surface-active for up to 4 months between emergence and mating (Holekamp \& Nunes, 1989), whereas males of other species only emerge a few days to a few weeks before mating (Michener, 1984).

We do not know of any other data describing variation in circulating oestrogen concentrations in sciurid rodents. Our data suggest that, as in common laboratory species, peak oestrogen concentrations in females of $S$. beecheyi occur during the brief ( $\sim 5 \mathrm{~h}$ : Holekamp \& Nunes, 1989) period of behavioural and morphological oestrus. Therefore, oestrogens probably have an important role in the mediation of these events in S. beecheyi, as in other mammals (e.g. Hart, 1971; Zemlan \& Adler, 1977; Feder, 1981).

Within-sex comparisons based on reproductive status in females showed that concentrations of the four hormones varied significantly with reproductive condition. The significantly higher testosterone concentrations in pregnant animals suggest a pattern of testosterone secretion similar to that observed in laboratory rats and mice, in which plasma androgen concentrations rise during pregnancy (e.g. Barkley et al., 1979; Soares \& Talamantes, 1982). Testosterone and prolactin concentrations varied with reproductive condition in males. Data presented here for nonreproductive males and females are not comparable, as they were collected in different months.

The differences between months in mean plasma concentrations of progesterone and prolactin found in killed animals were similar to those observed in the adjacent population of free-living individuals (Holekamp et al, 1988a,b). Circulating oestrogen concentrations in free-living animals were not measured because the volume of plasma required for the RIA was larger than the total plasma volume obtained via femoral venepuncture from wild $S$. beecheyi in earlier studies (Holekamp et al., 1988a, b). Mean peak progesterone concentrations in killed females were slightly lower than those in free-living animals (Holekamp et al., 1988b). The prolactin peak in the former group continued into May (Holekamp et al., 1988b), but plasma prolactin concentrations in our free-living squirrels were already declining in May. We suggest these differences might be related to differences between colonies with respect to the precise timing of reproduction; i.e. although a high degree of reproductive synchrony was observed within each monitored $S$. beecheyi colony at UCSC, there appeared to be substantially less synchrony between colonies. For example, in trapping concurrently in early April 1985 at 2 colonies separated by only $400 \mathrm{~m}, 4$ of 5 females from one colony were already lactating whereas 5 of 6 females from the others were still pregnant.

Although samples were small, significant transient increases in circulating gonadal steroid concentrations in juveniles of both sexes were observed in autumn 1984, 5-7 months after their births. Subsequent changes in 2 morphological indicators of male reproductive maturation, preputial separation and mature epididymal spermatozoa, suggested that the male testosterone 'pulse' in September might be functionally related to puberty as are brief rises in circulating gonadal steroid concentrations in other mammals (e.g. Goldman, 1981). Specifically, the transient increase in circulating testosterone observed in juvenile males immediately preceded initiation of testicular and penile development. Although young females exhibited what appeared to be an analagous rise in 
plasma oestrogen concentrations in November, 1984, no unambiguous morphological indicators of reproductive maturation in females were monitored. $S$. beecheyi of both sexes at UCSC participated in mating activities when they were 11-12 months old (Holekamp \& Nunes, 1989). By the start of the first mating season after their births, neither juvenile males nor females differed significantly from same-sex adults with respect to plasma concentrations of oestrogen or testosterone.

We thank J. Cheng, M. Conway, K. Green, S. Nunes, D. Polzine, T. Sloan, P. Smith, and L. Soon for their excellent assistance in the field. We also thank L. Ogren for many helpful suggestions during all phases of this research and $\mathrm{L}$. Smale for valuable comments. This work was supported by NRSA Postdoctoral Fellowship HD06553-02 to K. Holekamp.

\section{References}

Almeida, O.F.X. \& Lincoln, G.A. (1984) Reproductive photorefractoriness in rams and accompanying changes in the patterns of melatonin and prolactin secretion. Biol. Reprod. 30, 143-158.

Barkley, M.S., Geschwind, L.L. \& Bradford, G.E. (1979) The gestational pattern of estradiol, testosterone and progesterone in selected strains of mice. Biol. Reprod. 20, $733-738$.

Barnes, B.M. (1986) Annual cycles of gonadotropins and androgens in the hibernating golden-mantled ground squirrel. Gen. comp. Endocr. 62, 13-22.

Barnes, B.M., Kretzmann, M., Licht, P. \& Zucker, I. (1986) The influence of hibernation on testis growth and spermatogenesis in the golden-mantled ground squirrel (Spermophilus lateralis). Biol. Reprod. 35, 1289-1297.

Bushberg, D.M. \& Holmes, W.G. (1985) Sexual maturation in male Belding's ground squirrels: Influence of body weight. Biol. Reprod. 33, 302-308.

Davis, D.E. (1976) Hibernation and circannual rhythms of food consumption in marmots and ground squirrels. Rev. Biol. 51, 477-513.

Edge, E.R. (1931) Seasonal activity and growth in the Douglas ground squirrel. J. Mammal. 12, 194-199.

Feder, H.H. (1981) Estrous cyclicity in mammals. In Neuroendocrinology of Reproduction: Physiology and Behavior, pp. 279-348. Ed. N. T. Adler. Plenum Press, New York.

Fitch, H.S. (1948) Ecology of the California ground squirrel on grazing land. Am. Midl. Nat. 39, 513-596.

Goldman, B.D. (1981) Puberty. In Neuroendocrinology of Reproduction: Physiology and Behavior, pp. 229-239. Ed. N. T. Adler. Plenum Press, New York.

Grinnell, J. \& Dixon, J. (1918) Natural history of the ground squirrels of California. Bull. Calif. State Commun. Hort. 7, 597-708.

Hart, B.L. (1971) Facilitation by estrogen of sexual reflexes in female cats. Physiol. Behav. 7, 675-687.

Holekamp, K.E. \& Nunes, S. (1989) Seasonal variation in body weight, fat, and behavior of California ground squirrels (Spermophilus beecheyi). Can. J. Zool. 67, 1425-1433.

Holekamp, K.E., Nunes, S., \& Talamantes, F. (1988a) Circulating prolactin in free-living California ground squirrels (Spermophilus beecheyi). Gen. Comp. Endocr. 71, 484-492.
Holekamp, K.E., Nunes, S. \& Talamantes, F. (1988b) Patterns of progesterone secretion in free-living California ground squirrels (Spermophilus beecheyi). Biol. Reprod. 39, 1051-1059.

Kenagy, G. J. (1980) Interrelation of endogenous annual rhythms of reproduction and hibernation in the golden-mantled ground squirrel. J. comp. Physiol. 135, 333-339.

Keppel, G. (1973) Design and Analysis: A Researcher's Handbook. Prentice Hall, New Jersey.

Korenbrot, C.C., Hughtanieme, I.T. \& Weiner, R.I. (1977) Preputial separation as an external sign of pubertal development in the male rat. Biol. Reprod. 17, 298-303.

Licht, P., Zucker, I., Hubbard, G. \& Bosches, M. (1982) Circannual rhythms of plasma testosterone and luteinizing hormone levels in golden-mantled ground squirrels (Spermophilus lateralis). Biol. Reprod. 27, 411-418.

Lincoln, G. A. (1981) Seasonal aspects of testicular function. In The Testis, pp. 255-302. Eds H. Berger \& D. de Kretser. Raven Press, New York.

McKeever, S. (1964) The biology of the golden-mantled ground squirrel (Citellus lateralis). Ecol. Monogr. 34, $383-401$.

Michener, G.R. (1984) Age, sex, and species differences in the annual cycles of ground-dwelling sciurids: implications for sociality. In The Biology of GroundDwelling Squirrels, pp. 81-107. Eds J. O. Murie \& G. R. Michener. University of Nebraska Press, Lincoln.

Morton, M.L. \& Gallup, J.S. (1975) Reproductive cycle of the Belding ground squirrel (Spermophilus belding $i$ beldingi): Seasonal and age differences. Great Basin Natur. 35, 427-433.

Siwela, A.A. \& Tam, W.H. (1981) Metabolism of androgens by the active and inactive prostate gland, and the seasonal changes in systemic androgen levels in the gray squirrel (Sciurus carolinensis). J. Endocr. 88, 381-392.

Soares, M.J. \& Talamantes, F. (1982) Gestational effects on placental and serum androgen, progesterone and prolactin-like activity in the mouse. J. Endocr. 95, 29-36.

Thordarson, G., Holekamp, K.E. \& Talamantes, F. (1987) Development of an homologous radioimmunoassay 
for secreted prolactin from the California ground squirrel (Spermophilus beecheyi). Biol. Reprod. 36, 1186-1190.

Tomich, P.Q. (1962) The annual cycle of the California ground squirrel, Citellus beecheyi. Univ. Calif. Publ. Zool. 65, 213-282.

Wells, L.J. (1935) Seasonal sexual thythm and its experimental modification in the male of the thirteen-lined ground squirrel (Citellus tridecemlineatus). Anat. Rec. $62,409-447$.
Wesson, J.A., Scanlon, P.F., Kirkpatrick, R.L., Mosby, H.S. \& Butcher, R.L. (1979) Influence of chemical immobilization and physical restraint on steroid hormone levels in blood of white-tailed deer. Can. $J$. Zool. 57, 768-778.

Zemlan, F.P. \& Adler, N.T. (1977) Hormonal control of female sexual behavior in the rat. Horm. Behav. 9, 345-357.

Received 8 October 1990 